\title{
An Active Learning Seminar and Sequential Research Project Experience
}

\author{
Christopher J. Fariss
}

\begin{abstract}
I present two key components from a course designed to introduce undergraduate students to human rights: a set of group-based active learning tasks and an individual-based sequential research project. In the classroom, active learning opportunities allow students to creatively and collectively engage with course material. The sequential research project is a step-by-step guide for creating an original research paper. For the two components, the students draw from a set of primary source documents combined with additional readings to build knowledge in the classroom. With this new knowledge, the students generate ideas and content that they use to write a sequence of research essays about that course topic outside the classroom. In this manuscript, I describe the shared structure of the two learning components, discuss details about each of the sequential essays, present assessment data, and provide suggestions about how to adapt the course to other social science topics.
\end{abstract}




\section{Introduction}

Education shall be directed to the full development of the human personality and to the strengthening of respect for human rights and fundamental freedoms. It shall promote understanding, tolerance and friendship among all nations, racial or religious groups, and shall further the activities of the United Nations for the maintenance of peace. United Nations Declaration of Human Rights, Article 26.2.

I present two key components from a course designed to introduce undergraduate students to a set of broad questions related to human rights. The primary aim of the course is to help students understand what human rights are and how to use the scientific method to understand human rights and, through understanding, how to work towards strengthening human rights in communities around the world. Though the focus of this course is human rights, the structure of the course may be usefully applied in any substantively focused, upper division social science class.

The course structure follows the seminar style of a graduate class and, because of this, only sometimes makes use of lectures. To achieve excellence in the course, I ask my students to engage in two types of learning. In class, I ask my students to work together to understand course documents and readings, challenge each other in discussion, and to develop their own concepts about what human rights are, where they come from, and how to change them for the better. To accomplish these goals, I use an active learning approach, which includes instructional techniques that, by necessity, require the students to directly participate in the learning process. ${ }^{1}$ Outside of the classroom, I ask my students to write a sequence of interlocking essays that, once set together, constitute a first draft of a potential research paper or honor's thesis. These two learning components - active learning in the classroom and a sequential research project outside of the classroom - are designed to mutually reinforce one another by using the same set of primary source documents and examples from the assigned class readings.

By the end of the semester, students have collectively worked together through a set of ideas related to human rights using a shared collection of primary source human rights documents and the assigned readings. The research experience - the sequence of short essays related to the material discussed in-class yields well-structured, original human rights research papers of approximately 18 to 24 pages in length based on the same material. The sequence of essays begin with the selection of a global region and 2-3

\footnotetext{
${ }^{1}$ See for example Deslauriersa et al. (2019); Freeman et al. (2014).
} 
countries of interest. These cases facilitate the exploration of patterns of human rights behaviors within the selected country cases for the essays and provide material for discussion inside of the classroom. The exploration helps students to discover relationships between human rights of a specific type and particular features of the selected cases. With this material, the students develop a conceptually grounded explanation for a particular human rights pattern with a focus on the actors, the actors' actions, and the human rights outcomes that arise from the actions. Finally, the students conduct a descriptive analysis of related human rights data using the $\mathrm{R}$ programming language. At the end of the term, the students finalize their sequential research projects by writing a short introduction essay and conclusion essay that describe how each of the other component essays fit together and what was learned. Some students elect to complete two additional essays in order to earn a higher grade or possibly an A+. These additional components include the derivation of at least one hypothesis that is directly related to the model description essay and an essay that conducts additional data analysis using either qualitative evidence from new cases or quantitative data.

In this manuscript and appendix, I provide details about the organization of the active learning portion of the course and the sequential structure of the applied research experience. I also provide preliminary evidence from student response data that suggests the course is effective at helping students learn how to conduct research. I conclude with a discussion of options for applying the course structure to other social sciences topics.

\section{Active Learning in a Seminar Style Course}

The active learning component of the human rights course is facilitated by student led discussions of primary source material — human rights reports published annually by the US State Department and Amnesty International — and reading assignments. The set of primary source documents provides examples for the discussion and activities throughout the course and is the core empirical content that the students explore in several of the sequential essays described in the next section. Because many students do not have much experience with seminar style courses, I help them learn how to engage in this style of discussion using team-based activities.

I use a variety of active learning activities that make use of the seminar style format (see the Appendix 
for a detailed description of each learning activity). Three of the in-class group activities are crucial for both the in-class learning and also the sequential research project: the human rights categorization activity, the human rights model diagraming activity, and the R programming and learning activity. Next, I describe these three learning activities in conjunction with the sequential research project because, in addition to helping the students participate and learn during the in-class portion of the course, they also provide useful knowledge that the students use to complete their essays.

\section{The Sequential Research Project}

Just like a graduate seminar, the generation of original research is a focal point for my human rights class. ${ }^{2}$ However, instead of assigning a single research paper and expecting my students to understand how to generate such a document, I have created a series of short writing assignments that, when stitched together, constitute a first draft of a potential honor's thesis or similarly structured research project.

Table 1 lists the schedule of the active learning tasks and research essays. I use a variety of active learning activities in-class that make use of the seminar style format in this course but, because of space constraints, I only discuss three of them in detail. The appendix contains descriptions of all of the active learning tasks.

\footnotetext{
${ }^{2}$ There are many approaches to designing research focused courses (e.g., Baglione, 2008; Janz, 2016; Knoll, 2016)
} 
Table 1: Schedule of Active Learning Tasks and Essay Due Dates

\begin{tabular}{|c|l|l|}
\hline Class Week & Active Learning Tasks & Reach Project Essays \\
\hline Week 1 & Team-building ice-breakers & \\
Week 2 & Design a concept worksheet & \\
Week 3 & Human rights categorization ${ }^{1}$ & Region Essay \\
Week 4 & Actors, Actions, Outcomes worksheet & \\
Week 5 & Changing norms practice activity & \\
Week 6 & Contexts of repression activity & Case Comparison Essay part 1 (2 cases in 1 time period) \\
Week 7 & Changing norms worksheet & \\
Week 8 & Human rights model diagraming ${ }^{1}$ & \\
Week 9 & Data identification \& evaluation worksheet & \\
Week 10 & R programming and learning ${ }^{1}$ & Case Comparison Essay part 2 (1 case in 2 time periods) \\
Week 11 & R programming and learning ${ }^{1}$ & \\
Week 12 & Concept-Construct identification worksheet & Human Rights Model Description Essay \\
Week 13 & Concept-Construct identification worksheet & \\
Week 14 & In-class visualization critique & Human Rights Data Assessment and Visualization \\
Week 15 & & \\
Finals & & Introduction and Conclusion Essays \\
\hline & & Derivation of Hypotheses Essay ${ }^{2}$ \\
& & Additional Analysis Essay (qualitative cases or data analysis) ${ }^{2}$ \\
\hline
\end{tabular}

Note 1: Key active learning tasks that provide material used for the research essays (described in more detail below).

Note 2: Optional essays.

\subsection{Region Essay}

$10 \%$ of the course grade will be based on a 2-page essay in which you select a region of the world (e.g., Latin America, West Africa, Southeast Asia). In the essay, provide a brief summary that describes why you selected the specific region. What are the institutional or societal features about the region that are similar across countries? Which features seem to be different? You can also describe you are personally interested in this case. See chapter 1 in Sikkink (2011) for an example of what a longer version of this essay might look like. This short essay assignment is designed to help you focus on an area of the world in which human rights abuses are occurring. You should confine your discussion to the period from no earlier than 1946 to the present. Please cite any sources you use in your essay. A good place to start is the State Department Human Rights reports and the Amnesty International Human Rights reports. You will use this region to guide your selection of country cases and data in the Case Comparison Essay assignments (part 1 and part 2) and the Human Rights Data Assessment and Visualization assignment.

The purpose of this essay is to help my students focus on a set of comparable cases that are potentially similar along a number of contextual dimensions (e.g., language, institutional design, level of economic development, experience with colonization). Once the region is selected, the students will select 2 or 3 countries for cases in two additional essays. During class discussion, we consider why finding similar 
cases may be a useful strategy for identifying potentially meaningful differences between cases that, upon further investigation, might be related to different types of human rights practices. The region and case selection essays are designed to be exploratory, which becomes clearer as the sequence of essays progress. The exploratory essays provide context with which to build a conceptual explanation of a particular type of human rights process, which the students will tackle in the Human Rights Model Description Essay.

\subsection{Case Comparison Essay part 1 ( 2 cases in 1 time period)}

$10 \%$ of the course grade will be based on a 4-page case comparison essay in which you compare two human rights reports for different countries in the same year. The country cases you select should both be within the region identified in your Region Essay. Find the Amnesty International Human Rights report for the year you have selected and compare the description of the human rights abuses for the two cases. Are the patterns of human rights described in the reports similar or different? This assignment is designed to help you explore the similarities and differences in the specific details of the two cases. See chapter 2 in Sikkink (2011) for an example of what a longer version of this essay might look like.

The next step in the sequence of writing assignments requires the selection of two country cases in the same year. The students are required to use the primary source documents published annually by Amnesty International Human Rights and, optionally, the US State Department reports. During class discussion, we consider what the case specific details might reveal about particular patterns of human rights abuses or about why human rights are respected.

For this writing assignment, I ask the students to focus on one category of rights. How do they decide which category of rights to consider? They make use of information form one of the learning activities that takes place in-class. Prior to beginning this research essay, the students complete the first crucial inclass learning activity: the human rights categorization activity (see Appendix). For this in-class activity, students form small teams and categorize all 30 of the the articles contained in the UN Declaration of Human Rights. I do not require a specific number of categories but the usual number for each team is 3 and sometimes 4 or 5 . The teams tend to create similar groupings of UNDHR articles but there are always disagreements. The interesting part of the in-class discussion that follows this activity focuses on the disagreement over the placement of articles into specific categories. Once this activity is complete, 
the students have 3-5 categories of rights to choose from when delving into the case material for this essay and the ones that follow.

\subsection{Case Comparison Essay part 2 ( 1 case in 2 time periods)}

$10 \%$ of the course grade will be based on a 4-page case comparison essay in which you compare two human rights reports for the same country in two different year. Find the Amnesty International Human Rights reports for two different years at least 10 years apart. Compare the description of the human rights abuses contained in the two reports. Are the patterns of human rights described in the reports similar or different? This assignment is designed to help you explore the similarities and differences in the specific details of one case as it changes over time. See chapter 3 in Sikkink (2011) for an example of what a longer version of this essay might look like.

The second case comparison proceeds as the first. However, the students are required to select one case (usually one of the cases from part 1) and compare it over two time periods. The 10 year time period is a suggestion. During class discussion, we consider possible events that the students may have read about during the research and writing for the region essay or the first case comparison. If the students are aware of a specific critical juncture or potentially important event, then I encourage them to consider the cases in a year before and a year after the event. ${ }^{3}$

\subsection{Human Rights Model Description Essay}

10\% of the course grade will be based on a 3-4-page paper that describes a model of human rights. We will develop a model of human rights together in-class midway through the semester. The models/visual diagrams will be developed together in groups. Individually, each student will write a short essay that describes the logic of the models/visual diagrams. The essay does not need to describe every component of the models you design in-class. The core feature of this essay is the if-then-because statement. You must identify the conditions for variation in the human rights outcome that you focus on in your diagram. See chapter 4 in Sikkink (2011) in addition to the articles of the syllabus by Driscoll (2012), Mackie (1996), Smeulers (2004), or Wahl (2017) for examples of what a longer version of this essay might look like.

\footnotetext{
${ }^{3}$ Another theme we discuss is whether or not the primary source material produced in one year was produced in a similar manner in other years (e.g., Brysk, 1994; Clark, 2001; Eck and Fariss, 2018; Fariss and Dancy, 2017).
} 
This is likely the most challenging component of the sequence of writing assignments because it is the most unique. The initial creative process for this assignment is the second crucial in-class activity: the human rights model diagraming activity (see Appendix). For this activity, the students again work in teams to develop a visual diagram of a human rights process based on all of the material they have read and discussed. During the team-based work, I encourage the students to consider what each component of their diagram means. I also suggest that they consider the role of the actors, the actions of the actors, and the outcomes that those actions cause. The writing portion of this assignment begins several weeks later after we have read and discussed additional material from the class. This conceptual model forms an explanation that draws on the information that the students develop in their case comparisons and other information drawn from the reading material and in-class activities. Though the initial creative process takes place in teams, the writing portion is conducted independently.

\subsection{Human Rights Data Assessment and Visualization}

$10 \%$ of the course grade will be based on a 2-page assessment of human rights data. For this research project, you should find data about some aspect of human rights within the region you selected for the Region Essay. With the assistance of the instructor, identify a dataset that captures some aspect of human rights within your chosen region. Create a visualization of this data using the program $R$. On the first page of this assignment describe the data, where you obtained it, and what it measures. On the second page provide the visualization and an informative caption about the image. See the data visualization examples in Cordell (2017) or Fariss and Dancy (2017).

Prior to beginning this assignment, the students complete the third crucial in-class activity: the R programming and learning activity (see Appendix). We spend the first class considering data science as a profession and as a tool for understanding and changing the world for the better, discussing contemporary issues over data privacy, and downloading the R program and Rstudio program so that everyone is prepared to code during the tutorial in second and third class periods. During the second to last week of the course, we hold a data visualization critique (see Appendix). 


\subsection{Final Research Paper}

$10 \%$ of your grade will be based on a final paper. This is not so much a new writing assignment. Rather, it is a synthesis of the other essay that you have written over the course of the semester.You should write a 2-3 page introduction essay and a 1-2 page conclusion essay. The introduction essay should describe describe what a future reader will encounter in each of the subsequent parts of the full paper. The conclusion should summarize what the reader has learned by reading each of the sections. In other words, what are we going to discover (introduction) and what have we learned (conclusion)? See chapters 1 and 8 in Sikkink (2011) for longer examples of what these new portions of your final combined paper might look like.

The final paper is an opportunity to conduct revisions of the full paper. I emphasize this option throughout the course. However, I do not require my students to rewrite any sections if they do not fit together. Instead, I ask the students to describe what next steps they might take to better connect the sections together in their introduction essay and what they learned (or did not learn) in their conclusion essay.

\section{Discussion and Extensions}

I presented an innovative course structure that links together in-class active learning and out-of-class research. The active learning opportunities allow students to creatively and collectively engage with a set of shared primary source documents and course readings. The sequential research project provides a step-by-step guide for creating an original research paper. In the appendix, I present preliminary student assessment data that suggests the course structure is beneficial to student learning.

Applying the components of this class to another substantive domain requires selecting a set of shared documents and a unit-of-analysis. For my class, the units are country-years because the human rights reports are published annually for each country. However, an alternative unit-of-analysis that would work in my class are the human rights organizations themselves. There are many corpuses available in organization-archives and university-archives, which students might explore for both in-class activities and for applied research. ${ }^{4}$ The discussion of the course structure and evidence presented in this manuscript suggest that these two learning components are mutually reinforcing of one another and can be effectively adapted to the topics of other social science courses.

\footnotetext{
${ }^{4}$ For examples from my class, see Clark (2001); Eck and Fariss (2018); Hassan and O’Mealia (2018).
} 


\section{References}

Baglione, Lisa. 2008. "Doing Good and Doing Well: Teaching Research-Paper Writing by Unpacking the Paper.' PS: Political Science and Politics 41(3):595-602.

Brysk, Alison. 1994. "The Politics of Measurement: The Contested Count of the Disappeared in Argentina." Human Rights Quarterly 16(4):676-692.

Clark, Ann Marie. 2001. Diplomacy of Conscience. Princeton, NJ: Princeton University Press.

Cordell, Rebecca. 2017. "Measuring extraordinary rendition and international cooperation." International Area Studies Review 20(2):179-197.

Deslauriersa, Louis, Logan S. McCarty, Kelly Millerc, Kristina Callaghana and Greg Kestina. 2019. "Measuring actual learning versus feeling of learning in response to being actively engaged in the classroom." Proceedings of the National Academy of Sciences .

Driscoll, Jesse. 2012. "Commitment Problems or Bidding Wars? Rebel Fragmentation as Peace Building." Journal of Conflict Resolution 56(1):118-149.

Eck, Kristine and Christopher J. Fariss. 2018. "Ill Treatment and Torture in Sweden: A Critique of Cross-Case Comparisons." Human Rights Quarterly 40(3):591-604.

Fariss, Christopher J. and Geoff Dancy. 2017. "Measuring the Impact of Human Rights: Conceptual and Methodological Debates." Annual of Law and Social Science 13:273-294.

Freeman, Scott, Sarah L. Eddy, Miles McDonough, Michelle K. Smith, Nnadozie Okoroafor, Hannah Jordt and Mary Pat Wenderoth. 2014. "Active learning increases student performance in science, engineering, and mathematics." Proceedings of the National Academy of Sciences 111(23):8410-8415.

Hassan, Mai and Thomas O'Mealia. 2018. "Uneven Accountability in the Wake of Political Violence: Evidence from Kenya's Ashes and Archives." Journal of Peace Research 55(2):161-174.

Janz, Nicole. 2016. "Bringing the gold standard into the classroom: replication in university teaching." International Studies Perspectives 17(4):392-407.

Knoll, Benjamin R. 2016. "Learning by Doing: Mentoring Group-Based Undergraduate Research Projects in an Upper-Level Political Science Course." PS: Political Science and Politics 49(1):128131.

Mackie, Gerry. 1996. "Ending Footbinding and Infibulation: A Convention Account.” American Sociological Review 61(6):999-1017.

Sikkink, Kathryn. 2011. The Justice Cascade: How Human Rights Prosecutions Are Changing World Politics. The Norton Series in World Politics.

Smeulers, Alette. 2004. What Transforms Ordinary People into Gross Human Rights Violators? In Understanding Human Rights Violations: New Systematic Studies, ed. S. Carey and S. Poe. Aldershott: Ashgate pp. 239-253.

Wahl, Rachel. 2017. "No Justice, No Peace?: The Police, People of Color, and the Paradox of Protecting Human Rights.” Human Rights Quarterly 39(4):811-831. 


\section{Online Appendix: \\ An Active Learning Seminar and Sequential Research Project Experience for Undergraduate Human Rights Students}

\section{Contents}

$\begin{array}{ll}\text { A Active Learning Task Decriptions } & 1\end{array}$

A.1 Team-building ice-breakers . . . . . . . . . . . . . . . . . . . 2

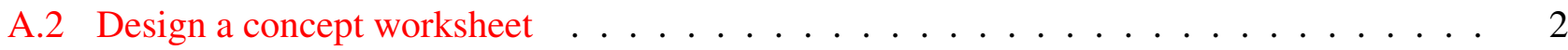

A.3 Human rights categorization . . . . . . . . . . . . . . . 3

A.4 Actors, Actions, Outcomes worksheet . . . . . . . . . . . . . 3

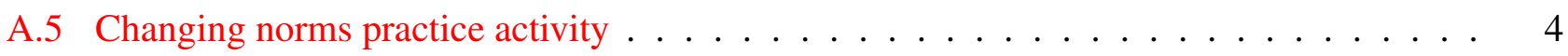

A.6 Contexts of repression activity . . . . . . . . . . . . . . . . . . 4

A.7 Changing norms worksheet . . . . . . . . . . . . . . . . 5

A.8 Human rights model diagraming . . . . . . . . . . . . . . . . . 5

A.9 Data identification \& evaluation worksheet . . . . . . . . . . . . . . 5

A.10 R programming and learning . . . . . . . . . . . . . . . . 6

A.11 Concept-Construct identification worksheet . . . . . . . . . . . . . . . 7

A.12 Data Visualization Critique . . . . . . . . . . . . . . . . . 9

B Additional Essay Components for the Sequential Research Project 10

B.1 Derivation of Hypotheses Essay . . . . . . . . . . . . . . . . . . . . 10

B.2 Additional Data Analysis Essay . . . . . . . . . . . . . . . . . 10

$\begin{array}{ll}\text { C Student Feedback } & 11\end{array}$ 


\section{Introduction to Appendix}

This supplementary appendix accompanies a new manuscript: "An Active Learning Seminar and Sequential Research Project Experience." In the sections below, I discuss each the active learning components in detail in section A, present two optional research essays in section B, and discuss student evaluation data about the course in section $\mathrm{C}$.

\section{A Active Learning Task Decriptions}

Below are descriptions of each of the activities learning actives presented in the schedule of tasks and essays in Table 1 in the main manuscript and reproduced here. Because of space constraints, I only reviewed the Human rights categorization, Human rights model diagraming, and $\mathrm{R}$ programming and learning activities in the main manuscript. Below, I review each of these tasks in more detail.

Table 1: Schedule of Active Learning Tasks and Essay Due Dates

\begin{tabular}{|c|l|l|}
\hline Class Week & Active Learning Tasks & Reach Project Essays \\
\hline Week 1 & Team-building ice-breakers & \\
Week 2 & Design a concept worksheet & \\
Week 3 & Human rights categorization ${ }^{1}$ & Region Essay \\
Week 4 & Actors, Actions, Outcomes worksheet & \\
Week 5 & Changing norms practice activity & \\
Week 6 & Contexts of repression activity & Case Comparison Essay part 1 (2 cases in 1 time period) \\
Week 7 & Changing norms worksheet & \\
Week 8 & Human rights model diagraming ${ }^{1}$ & \\
Week 9 & Data identification \& evaluation worksheet & \\
Week 10 & R programming and learning ${ }^{1}$ & Case Comparison Essay part 2 (1 case in 2 time periods) \\
Week 11 & R programming and learning & \\
Week 12 & Concept-Construct identification worksheet & Human Rights Model Description Essay \\
Week 13 & Concept-Construct identification worksheet & \\
Week 14 & In-class visualization critique & Human Rights Data Assessment and Visualization \\
Week 15 & & \\
Finals & & Introduction and Conclusion Essays \\
\hline & & Derivation of Hypotheses Essay ${ }^{2}$ \\
& & Additional Analysis Essay (qualitative cases or data analysis) ${ }^{2}$ \\
\hline
\end{tabular}

Note 1: Key active learning tasks that provide material used for the research essays.

Note 2: Optional essays are discussed in the appendix. All other essays are discussed in the main manuscript. 


\section{A.1 Team-building ice-breakers}

In week 1, I use a random number generator to place students into groups of 3-4 students. The students in each group need to learn the (1) name, (2) major, (3) year in college, (4) and something interesting, weird, or unique about each of the group members. The teams then present the information to the full class on behalf of the individual. In this way, no one introduces themselves. This activity is important because it introduces the students to the dominant mode of active learning that we make use of throughout the rest of the course.

\section{A.2 Design a concept worksheet}

In week 2, we read Seeing Like a State by James Scott (1998). This is a concept rich book that provides useful analogies for thinking about state institutions and state actions like repression.

The first chapter uses developments from 17th century German forestry science as a case to understand how state sanctioned institutional innovations have unintended consequences on the societies that are affected by these state choices. In particular, the author describes the actions that bureaucrats took to make the economic value of the forests and other land holdings legible to the central government. A key output of the bureaucrat's work was a cadastral map, a compressive land survey of ownership of all items of value within the government's domain and regimented forests which use monoculture planting to reshape forests based on the revenue yield of particular trees. A key features of the cadastral maps were the locations and output of these regimented forests, which were easily countable for revenue purposes. What was not easy for the bureaucrats to count or anticipate was the reactions of local populations or the interventions by nature into these altered ecological systems. In some cases, the unintended and unanticipated consequences were severe.

For the in-class activity, my students form teams. I ask each team to "design a forest." In the middle of this activity, I ask them to bring in any feature from the book chapter that they believe is relevant

for understanding the concepts from the book. What we discuss after the teams have finished creating each of their diagrams are the choices about what relevant information they decided to include and what was excluded. To bring home this point, I have the teams trade diagrams and then attempt to label the information in a diagram not of their own making. This is usually quite challenging. 
This learning activity helps impart three key lessons. First, concepts are simplifications of realty that, by design, cannot include all relevant detail. Second, concepts are useful for some cases or time periods but possibly not for others. Third, clearly articulating what the key features of the concept are is challenging but nonetheless critical for the transmission of knowledge and ideas. This is also true when attempting to identify this information in a written book or article. We return to these ideas throughout the rest of the course, especially for the Human rights categorization activity, the Human rights model diagraming activity, the Actors, Actions, Outcomes worksheet, and the Concept-Construct identification worksheet.

\section{A.3 Human rights categorization}

In week 3, students form small teams and categorize all 30 of the the articles contained in the UN Declaration of Human Rights. ${ }^{1}$ I do not require a specific number of groupings but the usual number for each team is 3 and sometimes 4 or 5 . The teams tend to create similar groupings of UNDHR articles but there are always disagreements. The interesting part of the in-class discussion that follows this activity focuses on the disagreement over articles into specific categories. Once this activity is complete, the students have 3-5 categories of rights to choose from when delving into the case material for this essay and the ones that follow. As described in the main manuscript, this in-class activity provides useful organizing information for several of the research essays.

\section{A.4 Actors, Actions, Outcomes worksheet}

In week 4 of the course, we discuss an article by Driscoll (2012). This is a useful article to introduce students to the actors, actions, and outcomes of a theoretical explanation. Sometimes I ask the questions below as a quiz or use them instead as part of a team activity. We apply the lessons from this activity throughout the course. These questions below form part of the Concept-Construct identification worksheet that I introduce later in the course during week 11 or week 12, which is included below.

1. Who are the main actors?

\footnotetext{
${ }^{1}$ The UN Declaration of Human Rights: https : / / www . un . org/en/universal-declaration-human-rights/.
} 
2. What types of actions can the actors take?

3. What are the outcomes or consequences of the actors actions individually and jointly?

4. What are the incentives of the actors?

\section{A.5 Changing norms practice activity}

In week 5, we discuss "Among the Thugs" by Bill Bufford (1992). During the discussion of this reading, we work together to change the norms for participating in a seminar discussion. During this discussion, I discourage the raising of hands prior to speaking. Instead, only the instructor now turned peer is obliged to do this. I encourage the students to speak to each other instead of me, the instructor, which facilitates peer-to-peer discussion. As I discuss in the main manuscript, the students in my experience tend to adopt these seminar style norms only begrudgingly and are quick to revert to the more comfortable patterns of behavior but it is an important feature of the class. We continue the discussion of the challenge of changing deeply embedded norms at several other points in the course, in particular when we discuss the readings by King (1963); Mackie (1996); Smeulers (2004); Wahl (2017).

\section{A.6 Contexts of repression activity}

In week 6, we add to the list of questions asked on the Actors, Actions, Outcomes worksheet. In addition to the questions already posed on the worksheet from week 4, I also ask: What other context do we need to know about to understand the actors and their choices? The readings from this week - Carey, Gibney and Poe (2010, Ch.4 and Ch.5), Davenport (2007), and Hassan and O’Mealia (2018) — are designed to help the students think about how specific cases or time periods of repression might be unique or possibly generalize to other cases or time periods. This is a theme that the students are already thinking about because of the case comparison essays discussed in the main manuscript and our discussions of several of the readings from earlier weeks in the semester. This in-class activity helps reinforce the idea of generalizability of a concept. We continue the discussion at several other points in the course. 


\section{A.7 Changing norms worksheet}

In week 7, we make use of the experiential knowledge generated during the Changing norms practice activity in week 5, to understand how actors attempted to change well established norms in several of our readings (e.g., King, 1963; Mackie, 1996; Smeulers, 2004; Wahl, 2017).

\section{A.8 Human rights model diagraming}

In week 8 , the students work in teams to develop a visual diagram of a human rights process based on all of the course material covered to date. This is a creative process. Because of this, I try to provide very little guidance during the first part of the idea generation during class. As the class period progresses, I begin to provide structural suggestions for the students about every 10-15 minutes during this class period. First, I ask the students to consider what each component of their diagrams mean. Second, I ask them to consider the role of the actors, the actions of the actors, and the outcomes that those actions cause. Because we have already spent time thinking about actors, actions, and outcomes, some of the student teams are already doing this. Third, I ask each team to define all of the essential components in their diagrams as part of their shared notes. Finally, I ask the students draw out their diagrams on the blackboard and present their models to the other teams. The material developed during this activity represents the starting point for the Human Rights Model Description Essay that I described in the main manuscript. The core analytical feature of the written essay that builds on this in-class activity, is the if-then-because statement. The students must identify the conditions for variation in the human rights outcome that they focus on in their diagram. They also need to think carefully about the logical connections they are establishing in their written essays. Creating this visually as a group is a useful starting point. Over the next several weeks, each student selects and refines part of their diagram to describe in words, with the core logical relationships clearly stated. This essay assignment and learning activity build on the earlier learning activities that involve thinking about and using concepts to understand complex processes.

\section{A.9 Data identification \& evaluation worksheet}

In week 9 of the course, we discuss articles by Brysk (1994) and Fariss (2018). These are useful articles

to introduce students to data used in social science research and the potential pitfalls associated with 
measuring difficult to observe processes like violence and human rights violations. Sometimes I ask the questions below as a quiz or use them instead as part of a team activity. As with the other in-class learning activities, we apply the lessons from this activity throughout the course. These questions below form part of the Concept-Construct identification worksheet that I introduce later in the course during week 11 or week 12, which is included below.

1. What is the unit-of-analysis? Does it represent an actor or some other type of case?

2. What is the main independent variable? How was it measured?

3. What is the main outcome variable or dependent variable? How was it measured?

4. What other variables do we need to know about to understand the relationship between the variables identified in the other questions?

5. Using the answers to the "How was it measured?" part of the answers from the questions above, do you have any concerns with the quality of the data being used for analysis?

\section{A.10 R programming and learning}

In week 10 and week 11, we learn about data science as a profession and as a tool for understanding and changing the world for the better. We spend the first class watching a few data science talks that make this argument, discuss contemporary issues over data privacy, and download the R program and Rstudio program so that everyone is prepared to begin coding during the second class. I then walk through a coding tutorial: easyRplots.R. The three functions from $\mathrm{R}$ used to complete the data visualization assignment are getwd(), read.csv(), and plot() or barplot(). During the tutorial, I repeat the following statement several times throughout the second and third days of this activity: "easy R plots dot R, it's easy." I have found that this silly mantra disarms the students somewhat, which helps them ask questions when they are lost. By the end of the course many of the students (but not all) discover the assignment is quite simple. The path to this discovery often requires students to learn from their failures before ultimately completing this assignment. This is in part why I require all students to visit my extended office hours at least once to discuss this assignment, discover and download data, and walk through their modified version of the R program I provide them in the coding tutorial. 


\section{A.11 Concept-Construct identification worksheet}

In week 12 and week 13, we combine and link together knowledge obtained from the learning that occurred using the Actors, Actions, Outcomes worksheet and the Data identification \& evaluation worksheet. In teams, the students use this new, combined worksheet to review several articles (Cordell, 2017; Dancy, 2018; Eck and Fariss, 2018; Hillebrecht and Straus, 2017). The knowledge obtained from this activity is crucial for those students who write the two optional essays. I present the prompts for the Derivation of Hypotheses Essay and the Additional Data Analysis Essay in Section B next. 


\section{Concept-Construct Worksheet}

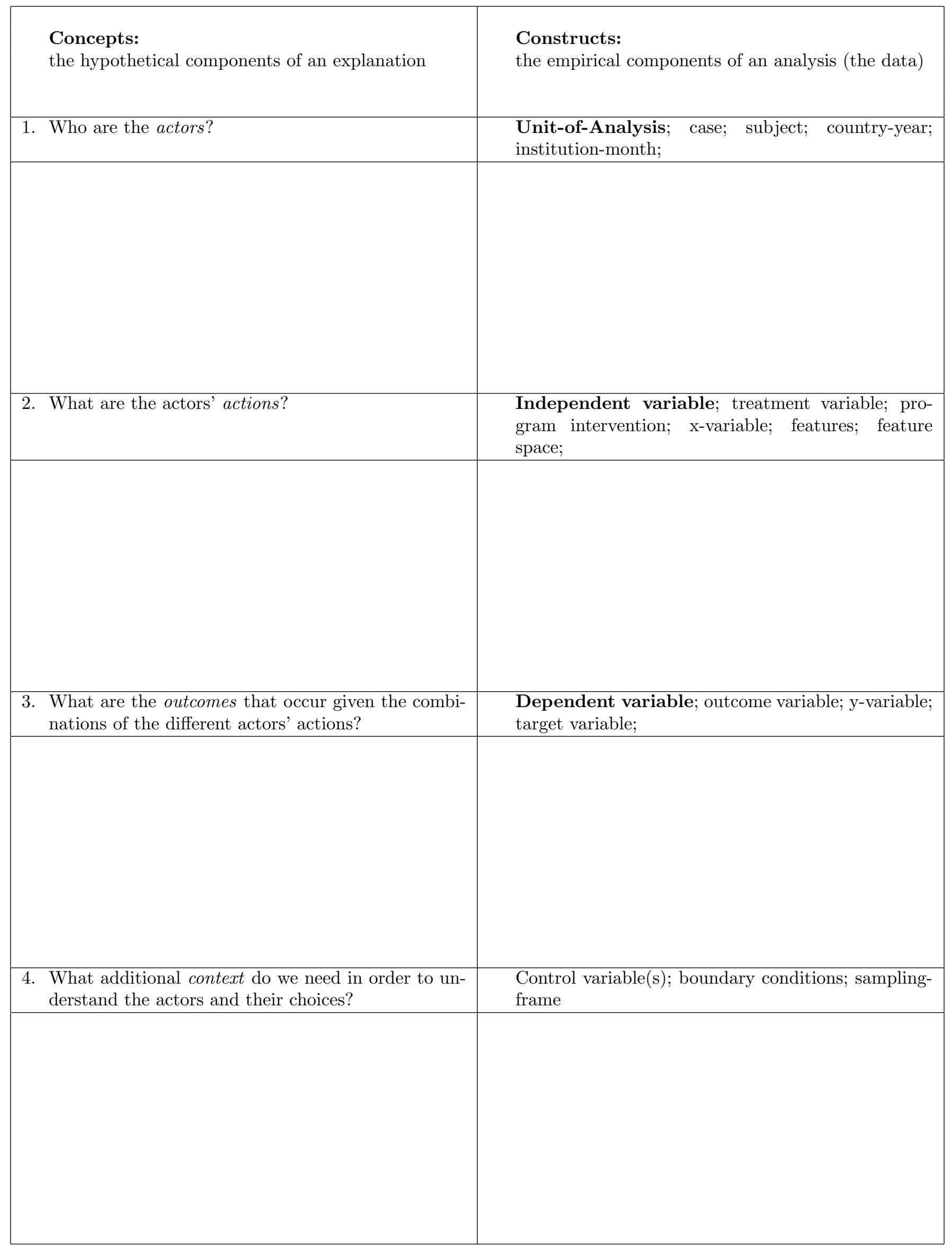




\section{A.12 Data Visualization Critique}

In week 14, which is usually the penultimate week of the course, we hold a data visualization critique in which we collectively discuss the Data Visualization graphs produced by each of my students. During the critique, we post all of the printed graphs around the room so that we can all view each of the data visualizations in detail. After viewing each of the student visualizations, each student presents their graph, describes what it contains, discusses any potential biases that might affect the observed patterns, and finally talks about potential next steps. 


\section{B Additional Essay Components for the Sequential Research Project}

\section{B.1 Derivation of Hypotheses Essay}

$+5 \%$ of your grade. Derive at least one hypothesis from your model description essay. Add the hypothesis to the end of this document. The hypothesis is a restatement on the relationship described in the if-then-because statement in the essay. The hypothesis will mirror the if-then part of this statement. Instead of being conceptual, the hypothesis will use the labels that correspond to the variables you will measure either with numerical data or categorical data.

\section{B.2 Additional Data Analysis Essay}

$+5 \%$ of your grade. Purposively select new cases for qualitative analysis or statistically analyze additional quantitative data. For the case study option, you should consult Seawright (2016) in order to understand the underlying reason for the new case you have selected. Unlike the first set of cases selected for the Case Comparison Essays, this new case is designed to assess if your model description works in new settings that were not used to develop your model of human rights. For examples of research from this course that use qualitative evidence from new cases: see chapter 5 in Sikkink (2011) in addition to the articles of the syllabus by Eck and Fariss (2018), or Hillebrecht and Straus (2017). For examples of quantitative analysis using data from this course, see chapter 6 in Sikkink (2011) in addition to the articles of the syllabus by Cordell (2017) or Dancy (2018). 


\section{Student Feedback}

Here, I present a preliminary assessment of course outcomes. I developed a short survey to collect additional information and feedback about the student's response to the structure of the course. 20 out of 23 students completed it. I was particularly interested to learn if any students had written a sequential set of essays in any other classes and if the students believed that this project might provide an effective guide for writing a research paper in the future.

I asked the students: "Have you ever written a series of essays that you combined together to form a final research paper?" The number was small but larger than I expected (yes=4, not sure=1, no=15). I also asked a follow up question for the students who responded "yes" to this question: "If you answered 'yes' above, do you recall the course title or number?" The reported classes were from Urban Planning, Ecology, and an independent topics course in Political Science. The fourth student wrote that they were "not sure". About $75 \%$ of my students are graduating seniors and the rest are juniors. The results from the student responses suggest that the structure of this course is a relatively unique given the average number of course credits the students in my class have completed upon entering my course in what is often their final term.

I also asked: "If asked to write a research paper in the future, would you use the essay structure from this as a guide?" (yes $=11$, not sure $=8$, no=1). Table 2 displays the cross-tabulation between experience in writing a sequential essay (rows) and intention to use the experience to help write future research papers (columns). The results suggest, of those students who have not written a sequence of research essays before, that they believe that the structure of the project may be beneficial in future research projects (yes=0.57, not sure $=0.36$, no=0.07). Written comments provide additional support for this conclusion.

The final open ended question I asked of my students was: "Are there any other comments or constructive suggestions that you have for the structure of the seminar discussions or the structure of the essay assignments?" One student wrote: "I liked how all the papers we wrote fit together - it made me put more thought into each of them because I knew I would need to go back to it later."

I did not ask directly how the sequential essay informed student engagement with assigned readings or the in-class activities (I plan to ask such a question in the future). However, some of the student comments about the relationship between the two main components of the course are instructive here as 
well. One student commented that the sequential essay structure was "great and made reading the other papers easier." Another student noted how the in-class and out-of-class components of the course were mutually reinforcing: "[o]verall, I really enjoyed the style of this class compared to other lecture-based classes. At first, I was a little hesitant because I didn't know what to expect but all the topics/readings blended really well together to culminate in a clearer picture of what human rights look like today."

Table 2: Cross-tabulation: Relationship between prior experience in writing a sequential essay and intention to use the experience to help write future research papers

\begin{tabular}{|l|rrr|}
\hline & \multicolumn{3}{|c|}{ Intention } \\
\hline Experience & no & not sure & yes \\
\hline no & 1 & 5 & 8 \\
not sure & 0 & 0 & 1 \\
yes & 0 & 3 & 2 \\
\hline
\end{tabular}




\section{References}

Brysk, Alison. 1994. "The Politics of Measurement: The Contested Count of the Disappeared in Argentina." Human Rights Quarterly 16(4):676-692.

Bufford, Bill. 1992. Among the Thugs: The Experience, and the Seduction, of Crowd Violence. W. W. Norton.

Carey, Sabine C., Mark Gibney and Steven C. Poe. 2010. The Politics of Human Rights: The Quest for Dignity. Cambridge, MA: Cambridge University Press.

Cordell, Rebecca. 2017. "Measuring extraordinary rendition and international cooperation." International Area Studies Review 20(2):179-197.

Dancy, Geoff. 2018. "Deals with the Devil? Conflict Amnesties, Civil War, and Sustainable Peace." International Organization 72(2):387-421.

Davenport, Christian. 2007. State Repression and the Domestic Democratic Peace. New York: Cambridge University Press.

Driscoll, Jesse. 2012. "Commitment Problems or Bidding Wars? Rebel Fragmentation as Peace Building." Journal of Conflict Resolution 56(1):118-149.

Eck, Kristine and Christopher J. Fariss. 2018. "Ill Treatment and Torture in Sweden: A Critique of Cross-Case Comparisons.” Human Rights Quarterly 40(3):591-604.

Fariss, Christopher J. 2018. "Human Rights Treaty Compliance and the Changing Standard of Accountability." British Journal of Political Science 48(1):239-272.

Hassan, Mai and Thomas O'Mealia. 2018. "Uneven Accountability in the Wake of Political Violence: Evidence from Kenya's Ashes and Archives.” Journal of Peace Research 55(2):161-174.

Hillebrecht, Courtney and Scott Straus. 2017. "Who Pursues the Perpetrators?: State Cooperation with the ICC." Human Rights Quarterly 39(1):162-188.

King, Martin Luther Jr. 1963. "Letter from a Birmingham Jail.” Letter.

Mackie, Gerry. 1996. "Ending Footbinding and Infibulation: A Convention Account." American Sociological Review 61(6):999-1017.

Scott, James C. 1998. Seeing Like a State: How Certain Schemes to Improve the Human Condition Have Failed. New Haven: Yale University Press.

Seawright, Jason. 2016. "The Case for Selecting Cases That Are Deviant or Extreme on the Independent Variable." Sociological Methods \& Research 45(3):493-525.

Sikkink, Kathryn. 2011. The Justice Cascade: How Human Rights Prosecutions Are Changing World Politics. The Norton Series in World Politics.

Smeulers, Alette. 2004. What Transforms Ordinary People into Gross Human Rights Violators? In Understanding Human Rights Violations: New Systematic Studies, ed. S. Carey and S. Poe. Aldershott: Ashgate pp. 239-253. 
Wahl, Rachel. 2017. "No Justice, No Peace?: The Police, People of Color, and the Paradox of Protecting Human Rights." Human Rights Quarterly 39(4):811-831. 